\title{
Efficiency assessment of procurement by the organization and planning of civil works
}

\author{
Anna Minnullina, ${ }^{1, *}$ \\ ${ }^{1}$ Tyumen Industrial University, Volodarskogo str., 38, Tyumen, 625000, Russia
}

\begin{abstract}
The article deals with the algorithm for the efficiency estimating of procurement, based on the author's set of individual indicators, the calculation of which will identify existing problem areas in procurement. To interpret the results of the calculations the author proposes Harrington scale, which is based on the idea of converting the obtained values of the indicators in the dimensionless desirability scale. The result of evaluating the effectiveness of procurement is shaped map of procurement path, which is offered as a tool for assessing the efficiency of procurement in the dynamics.
\end{abstract}

\section{Introduction}

Purchases are the starting point for the production activity of any company. However, against the background of the active dissemination of a supply chain management concept, considerable part of Russian companies is paying excessive attention to the inventory management, building of distribution system and other functional logistics, thus underestimating the need to improve procurement activities in view of its contribution to the effectiveness of organization's activity as a whole.

Increasing the procurement efficiency is a priority for the development of economic activities of the organization. To solve the problem it is required advanced grounded system of efficiency indicators, showing the main aspects of management decisions to the procurement processes.

Nowadays in the special literature devoted to the study of logistics and supply chain management, various authors are proposing to use a significant number of indicators for measuring the efficiency of procurement, unrelated (Butrin A.G., Fedko V.P. and BondarenkoV.A.,Scherbakov V.V. et al.) [1-3]. Kanke A.A. and I.P. Koshevaya [4] propose to evaluate the efficiency of procurement by means of indicators such as: inventory turnover of means of production; the degree of maintenance with products for industrial and technical purpose and the net logistic support production.

Some authors have formed comprehensive indicators for assessing procurement activity of organization: complex index of fulfillment of obligations to supply with material resources (Savenkov T.I.), the integrated economic efficiency of the optimization of material flows (Blank I.A.). Lebedev Y.G. [5] to assess the efficiency of the procurement using the input contribution rate (procurement) of logistics, based on the ratio of costs to it

*Corresponding author: minnullinaay@yandex.ru 
and the cost of purchase of raw material resources that characterizes the procurement activity only from the standpoint of profitability. The author of many textbooks for high schools and scientific papers [6], Tyapukhin A.P., proposes as indicators for assessing the efficiency of procurement: the uniformity of supply, the rhythm of supply, a percentage of the total amount of the claims to the provider for quality resource supply, the coefficient of variation of supply. However, it should be emphasized that these figures are not relevant and accordingly have no sense for companies with seasonal kinds of the construction work. The same can be said about such proposed by L.B. Mirotin [7] criteria, as the optimal size of the purchase; volume of purchased products; the frequency of placing orders; delivery frequency; delivery interval.

Foreign authors give the most popular among the directors in US companies MARcriteria - the criteria for assessment of efficacy, of which there are about 20 (M.R. Linders and H.E. Fearon, D. Bauersoks, Closs A.D.) [8,9]. However, most of these criteria do not apply to the Russian practice of commercial activities of the organization.

It is worth noting that many authors of scientific papers refer to the need to assess the efficiency of procurement, but don't give any indicators (Y.A. Borodina and O.M. Syardova) [10]. Sysolyatin A.V. in his article [11] concludes that the feasibility of a comprehensive evaluation of the procurement of services, establishing an assessment of control over the activities of the department on a sufficiently controversial up to date performance - price, time and reliability of the supplier. Such criteria for evaluating the effectiveness of procurement are given by Lukinskiy V.S. and V.I. Sergeev in their works [12-14].For efficient operation of the procurement department of labor necessary to develop a system of incentives [15].It is also necessary to emphasize that some of the indicators proposed by various authors take into account only the results of certain operations in the procurement process (e.g., the timing of execution of the order, the number of suppliers; payment terms, delivery time, delivery frequency, the amount of bound capital, delivery reliability; delivery period), rather than efficiency [16].Evaluation of the effectiveness of procurement management is a multifaceted task, the complexity of which is the fact that not all indicators of procurement can be quantified. In this case, many of the authors of logistics studies offer the use of the method of peer review.

\section{Methods}

Considering the advantages and disadvantages of the considered indicators for assessing the efficiency of procurement, there are formed the following constraints to the author's set of indicators: indicators should reflect a quantitative assessment; indicators should take into account both external and internal factors affecting the procurement; the number of indicators included in the system, should enable a sufficiently complete analysis, but do not overload the system, in order to avoid information redundancy; the proposed indicators should be universal, i.e. suitable for the evaluation of the procurement activities of the organizations of any branch; procedure should be easy to use to facilitate the collection of data and calculations to be able to implement in practice; indicators should be grouped into separate units to assess the effectiveness of procurement in different sections; calculation of the results must be presented in a comprehensive index for easy comparison of their dynamics.

To evaluate the efficiency of procurement author offers a set of individual indicators, divided into two groups for assessing the degree of fulfillment of the goals and targets for the different stages of procurement: individual indicators of procurement efficiency; individual indicators of procurement quality and performance.

It is important to note that, from the author's position, these groups of individual indicators should also be divided into two groups to take into account influence of factors 
of internal and external environment of the company. In the future, after evaluating the effectiveness of procurement it will give the opportunity to generate development path for procurement more accurately.

Group 1: individual procurement efficiency indicators, taking into account environmental factors. Cost represents the degree of minimization of costs for the individual stages of the procurement process and procurement in general. On this basis for the calculation of this group of indicators it is proposed to estimate the total expenses of the organization, the total cost of all the procurement process and put it to the elements. In addition to the direct costs for the purchase must be distributed and the cost of logistics services intermediaries (freight forwarders, carriers, etc.).

1. The proportion of costs for the purchase of i-material resource in the general expenses of organization

$$
p_{t}^{\text {pur }}=\frac{\sum_{i=1}^{n} C_{i t}^{\text {pur }}}{\sum_{i=1}^{n} C_{i t}^{\text {total }}} \rightarrow \min
$$

$C_{i t}^{\text {pur }}$ - costs for the purchase of the i-material resource for the $\mathrm{t}$ period; $C_{i t}^{\text {total }}$ - total expenses of the organization for the t-period.

2. The proportion of financial resources aimed at the purchase of material resources in a competitive way in the total volume of purchases

$$
p_{i}^{\text {comp }}=\frac{\sum_{i=1}^{n} E_{i t}^{\text {comp }}}{\sum_{i=1}^{n} E_{i t}^{\text {pur }}} \rightarrow \max
$$

$E_{i t}^{c o m p}$ - the number of contracts for the purchase of the i-material resource, concluded in a competitive way; $E_{i t}^{\text {pur }}$ - the total number of contracts for the purchase of the i-material resource.

3. The proportion of the cost of logistics intermediaries services in the procurement of material resources

$$
\mathrm{p}_{\mathrm{t}}^{\text {inter }}=\frac{\sum_{\mathrm{i}=1}^{\mathrm{n}} \mathrm{C}_{\mathrm{it}}^{\mathrm{inter}}}{\sum_{\mathrm{i}=1}^{\mathrm{n}} \mathrm{C}_{\mathrm{it}}^{\text {pur }}} \rightarrow \min
$$

$C_{i t}^{\text {inter }}$ - the cost of intermediaries services in the procurement process of the i-material resource for the t-period

Group 2: individual indicators, taking into account the internal environment of the organization. The main object of the procurement budget may include the cost of purchased material resources, transportation costs associated with the quality of the subject of procurement issues, breach of delivery terms, the cost of customs and other charges, as well as the cost of procurement management, associated personnel engaged in the procurement, renting premises, fixed assets involved in the procurement process, the acquisition of thirdparty services, inventory management.

Savings in procurement can be achieved by purchasing department managers due to lower prices for material resources (reception of the discount from the price), or the volume of purchases, changes in procurement processes, quality and security of supply (the exact implementation of supply in accordance with the terms).

4. The level of implementation of procurement budget plan

$$
p_{t}^{b u d g}=\frac{\sum_{i=1}^{n} \frac{\operatorname{Pr}_{i t}^{a c t}}{\operatorname{Pr}_{i t}^{p l}}}{n} \rightarrow \max
$$


$P r_{i t}^{a c t}$ - the actual price (budget) of procurement of i-material resource in the t-period; $P r_{i t}^{p l}$ - planned price (budget) of procurement of $\mathrm{i}$-material resource in the t-period; $\mathrm{n}$ - the number of species of planned to be bought material resources.

5. The level of the contribution of employees in procurement activities

$$
p_{t}^{\% \text { empl }}=\frac{\sum_{i=1}^{n} \frac{E_{i t}^{\text {\% pur }}}{E_{i t}^{\text {pur }}}}{n} \rightarrow \min
$$

$E_{i t}^{\% \text { pur }}$ - the amount of funds saved by employees as a result of price discounts, consolidation of procurement volumes and al. for the t-period; $E_{i t}^{\%}$ pur - the amount of funds allocated for the purchase of the i-material resource for the t-period

6. The proportion of administrative costs of the procurement department in the total volume of purchases

$$
p_{t}^{a d m}=\frac{\sum_{i=1}^{n} C_{i t}^{a d m}}{\sum_{i=1}^{n} C_{i t}^{\text {pur }}} \rightarrow \min
$$

$C_{i t}^{a d m}$ - administrative costs associated with purchasing the i-material resource for the $\mathrm{t}$ period.

Group 3: individual quality and procurement efficiency indicators, taking into account the influence of environmental factors. Quality of procurement in the interaction with the environment involves assessing the level of waste and claims in the total amount of purchases that characterizes the interaction of the organization with logistics providers and intermediaries as participants in the supply chain.

7. The proportion of waste in the total amount of resources supply

$$
p_{t}^{\text {waste }}=\frac{\sum_{i=1}^{n} E_{i t}^{\text {waste }}}{\sum_{i=1}^{n} E_{i t}^{\text {pur }}} \rightarrow \min
$$

$E_{i t}^{\text {waste }}$ - the amount of the i-material resource with defects, delivered for the t-period in value terms

8. The proportion of reliable participants of material resources supply chain

$$
p_{j t}^{r e l}=\frac{L_{j t}^{r e l}}{L_{j t}^{\text {total }}} \rightarrow \max
$$

$L_{j t}^{r e l}$ - the number of participants in the supply chain who have completed applications for material resources, fully corresponding nomenclature, timing, quantity and quality during the t-period; $L_{j t}^{\text {total }}$ - the total number of participants during the t-period.

9. The proportion of violations of material resources delivery terms

$$
p_{t}^{\text {viol }}=\frac{\sum_{i=1}^{n} \frac{V_{i t}^{\text {viol }}}{V_{i t}^{\text {total }}}}{n} \rightarrow \min
$$

$V_{i t}^{v i o l}$ - the number of deliveries of i-material resources, with violations of the supply terms during the t-period; $V_{i t}^{\text {total }}$ - the total number of deliveries of i-material resource during the t-period

Group 4: individual indicators of efficiency and quality of procurement, taking into account the internal environment of the organization. The quality of the performed work depends on the activity of managers of the purchasing department, and the performance of 
the procurement process includes evaluating the speed of procurement operations and productivity of personnel involved in the procurement process. The quality of the purchased material resources and work of the procurement department is assessed by management in conjunction with specialists of departments of production and control.

10. Percentage of satisfaction of domestic consumers of material resources

$$
\begin{gathered}
I_{\text {sat }}=\left(1-p_{\text {unf.app }}\right) \times\left(1-p_{\text {def.app }}\right) \times\left(1-p_{\text {unsat .app }}\right) \times\left(1-p_{\text {unsat .qual }}\right) \rightarrow \max \quad(10) \\
p_{\text {unf.app. }}=\frac{N_{\text {unf.app }}}{N_{\text {total .app }}}, p=\frac{N_{\text {def.app }}}{N_{\text {made .app }}}, p_{\text {unsat .app }}=\frac{N_{\text {unsat .vol }}}{N_{\text {made .a }}}, p_{\text {unsat .qual }}=\frac{N_{\text {unsat .qual }}}{N_{\text {made .app }}}
\end{gathered}
$$

$p_{\text {unf.app }}$ - the proportion of unfulfilled applications through the purchasing department's fault; $p_{\text {def .app }}$ - the proportion of deferred applications through the fault of the purchasing department; $p_{\text {unsat app }}$ - the proportion of applications, not fully satisfied in terms through the fault of the purchasing department; $d_{\text {unsat .qual }}$ - the proportion of applications, which are not fully satisfied with the quality of the resources through the fault of the purchasing department; $N_{\text {unf.app }}$ - the number of unfulfilled applications; $N_{\text {total .app }}$ - the total number of requests from internal customers (branches); $N_{\text {def.app }}$ - the proportion of deferred applications; $N_{\text {made app }}$ - the total number of applications made by the purchasing department; $N_{\text {unsat .vol }}$ - the proportion of applications which are not fully satisfied with the volume; $N_{\text {unsat .qual }}$ - the proportion of applications which are not fully satisfied with the quality.

11. Productivity of personnel involved in procurement activities

$$
p_{t}^{\text {pers }}=\frac{\sum E_{i t}^{\text {cont }}}{N_{\text {pur }}^{\text {pers }}} \rightarrow \max
$$

$E_{i t}^{c o n t}$ - value of the signed by the procurement department contracts for the purchase of resources during the t-period; $N_{\text {pur }}^{\text {pers }}$ - contingent of employees of purchasing department. 12. The total turnover of material resources

$$
T_{t}^{\text {invent }}=\frac{V}{\sum_{i=1}^{n} C_{i t}^{\text {invent }}}, \rightarrow \max
$$

$V$ - the volume of goods sold during the t-period; $C_{i t}^{\text {invent }}$ - cost of inventory in stock for t-period.

To calculate the complex indicator for each group of indicators it is necessary to bring individual indicators to a common dimension and orientation. For this purpose, individual indicators should result in comparable form based on a linear scaling in the interval $[0,1]$. As an extreme range of the zoom Interval are taken the best and worst values of individual indicators characterizing the results of procurement activities.

In assessing the efficiency of procurement are taken into account data for the calculation of individual parameters characterizing the procurement activity for a certain period of time. Mathematically, the procedure of normalization of individual indicators:

$$
\begin{aligned}
& p_{k l}^{\min }=\min _{1 \leq t \leq T} p_{k l t} \\
& p_{k l}^{\max }=\max _{1 \leq t \leq T} p_{k l t}
\end{aligned}
$$




$$
P_{k l t}\left\{\begin{array}{l}
\frac{p_{k l t}-p_{k l}^{\min }}{p_{k l}^{\max }-p_{k l}^{\min }}, k \in M_{1} \\
\frac{p_{k l}^{\max }-p_{k l}^{\min }}{p_{k l}-p_{k l}^{\min }}, k \in M_{2}
\end{array}\right.
$$

$p$ - the actual value of $\mathrm{k}$ individual indicator during t-period; $p_{k l}^{\min }$ - the lowest actual value of the $\mathrm{k}$ individual indicator (lower limit of the zoom Interval); $p_{k l}^{\max }-$ the highest actual value of $\mathrm{k}$ individual indicator (upper limit of the zoom Interval); $P_{k l t}$ - normalized value of $\mathrm{k}$ individual indicator for the t period; $\mathrm{K}$ - the total number of individual indicators in the group; $t=\overline{1, T}$ - the period taken into account for the calculation of individual indicators; $L=\overline{1, L}-$ the sequence number of the supply chain participant; $\lambda_{i}-$ the importance of an individual indicator in the group.

To account the direction of values of individual indicators characterizing the negative processes it is necessary to determine the reciprocal. Calculation of the complex index is the definition of compromise value that indicates a certain connection of individual indicators conjunction:

$$
F_{t l}^{k}=\sum_{i=1}^{n} \lambda_{i} * P_{k l t} \rightarrow \max
$$

Calculation of complex index for each group will make it possible to identify the weaknesses in the procurement activity. The values of complex indices are in the range from 0 to 1 . For the interpretation of the values for the complex index of the efficiency of procurement evaluating we use a Harrington scale, which is based on the idea of converting the obtained values of the indicators in the dimensionless desirability scale.

Sector 1 "Improving of procurement activities" is in the range from 0 to 0.37 . Value of complex indices in this sector is characterized by an unfavourable condition and a low estimate of efficiency in procurement. In this case it is necessary to make management decisions on how to improve the internal and external procurement components.

Sector 2 "Monitoring of procurement activities" This sector can be noted as the most dangerous, because it requires the analysis of the dynamics of values. When the dynamics of the complex indices values is negative, it is possible to hit the sector 1, which will require the adoption of certain decisions concerning measures to improve procurement.

Sector 3 "support of procurement activities" describes the strengths of procurement activity. The sector is in the range from 0.8 to 1 . If you get the values of complex indices in this sector the main task of management of the organization is to keep the positions in procurement management. At the final stage it is constructed the map of procurement activity development path. The values obtained for complex indices are indicators for assessing the efficiency of procurement, taking into account internal and external environment. By the systematic evaluation of the procurement effectiveness, the map can reflect the dynamics of changes in the values of indicators, which reflect development path for procurement activity of the company.

\section{Assessment and Results}

In order to confirm the applied nature of the recommendations we have evaluated the effectiveness of procurement of road construction company JSC "TODEP" Tyumen. The basis of production efficiency of road-building organizations is made by the manufactured products (such as road-building, asphalt, etc.), that meets consumers' demands $[17,18]$. However, apart from the quality of the raw material used as the main criterion of procurement efficiency, it is important to take into account the internal environment of the road sector organizations. Evaluation of the efficiency of procurement carried out according 
to the main economic activity of the branches of JSC "TODEP": Tyumen RRCD (road repair and construction department), Zavodoukovsk RRCD, Vagaysk RRCD, Yalutorovsk and Ishim RRCD (Table 1, 2).

Table 1. Assessment of the procurement of material resources effectiveness in the branches of JSC "TODEP" taking into account the influence of environmental factors.

\begin{tabular}{|l|c|c|c|c|c|c|}
\hline \multirow{2}{*}{ Indicators } & \multicolumn{5}{c|}{$\begin{array}{c}\text { Subjects of the effectiveness } \\
\text { procurement evaluating }\end{array}$} \\
\cline { 2 - 7 } & $\mathrm{A}$ & $\mathrm{B}$ & $\mathrm{C}$ & $\mathrm{D}$ & $\mathrm{E}$ \\
\hline $\begin{array}{l}\text { The proportion of costs for the purchase of material } \\
\text { resources in the general expenses of organization }\end{array}$ & & & & & \\
\hline $\begin{array}{l}\text { The proportion of funds directed to the procurement in } \\
\text { competitive way in the total amount }\end{array}$ & & 0.65 & 0.78 & 1 & 0.83 & 0.83 \\
\hline $\begin{array}{l}\text { The proportion of the costs for the logistical services } \\
\text { intermediaries in the procurement of resources }\end{array}$ & & & & & \\
\hline Comprehensive index of procurement efficiency & 0.72 & 0.76 & 1 & 0.92 & 0.85 \\
\hline The proportion of waste in the total supply volume & 0.43 & 0.80 & 0.90 & 0.92 & 0.80 \\
\hline The proportion of reliable supply chain participants & 0.5 & 1 & 0.76 & 0.65 & 0.6 \\
\hline $\begin{array}{l}\text { The proportion of violations of material resources delivery } \\
\text { terms }\end{array}$ & & 0.48 & 0.94 & 1 & 0.6 & 0.45 \\
\hline Comprehensive index of procurement quality & 0.47 & 0.98 & 0.79 & 0.65 & 0.68 \\
\hline
\end{tabular}

Formal designations subjects of the effectiveness procurement evaluating: A - Tyumen RRCD, B - Vagaysk RRCD, C - Yalutorovsk RRCD, D - Zavodoukovsk RRCD, E - Ishim RRCD.

Table 2. Assessment of the procurement of material resources effectiveness in the branches of JSC "TODEP" taking into account the influence of factors of the internal environment.

\begin{tabular}{|l|c|c|c|c|c|c|}
\hline \multirow{2}{*}{ Indicators } & \multicolumn{5}{c|}{$\begin{array}{c}\text { Subjects of the effectiveness } \\
\text { procurement evaluating }\end{array}$} \\
\cline { 2 - 7 } & $\mathrm{A}$ & $\mathrm{B}$ & $\mathrm{C}$ & $\mathrm{D}$ & $\mathrm{E}$ \\
\hline The level of performance of the procurement budget plan & 0.85 & 0.88 & 1 & 0.8 & 0.95 \\
\hline $\begin{array}{l}\text { The level of the contribution of employees in the } \\
\text { procurement activities of the organization }\end{array}$ & 0.4 & 0.48 & 0.82 & 0.55 & 1 \\
\hline $\begin{array}{l}\text { The proportion of the administrative costs of the } \\
\text { procurement personnel in the total amount of purchases }\end{array}$ & 0.6 & 0.28 & 1 & 0.46 & 0.69 \\
\hline Comprehensive index of procurement efficiency & 0.62 & 0.55 & 0.94 & 0.60 & 0.88 \\
\hline The share of satisfied domestic consumers of resources & 0.24 & 0.34 & 0.28 & 1 & 0.5 \\
\hline Productivity of personnel involved in procurement activities & 0.3 & 0.5 & 0.3 & 1 & 0.45 \\
\hline The total resource inventory turnover & 0.5 & 1 & 0.45 & 0.8 & 0.85 \\
\hline Comprehensive index of procurement quality & 0.35 & 0.61 & 0.34 & 0.93 & 0.60 \\
\hline
\end{tabular}

On the basis of the assessment of the procurement efficiency the author composed the card of development paths of procurement activity, which allows to assess visually the thrust of required changes (Table 3).

Table 3. Map of the procurement developing path for the branches of JSC "TODEP".

\begin{tabular}{|l|c|c|c|c|}
\hline \multicolumn{1}{|c|}{ Indicators } & Environment & $\begin{array}{c}\text { Improving of } \\
\text { procurement } \\
\mathbf{( 0 - 0 . 2 )}\end{array}$ & $\begin{array}{c}\text { Monitoring of } \\
\text { procurement } \\
\mathbf{( 0 . 3 7 - 0 . 6 4 )}\end{array}$ & $\begin{array}{c}\text { Support of } \\
\text { procurement } \\
\mathbf{( 0 . 8}-\mathbf{- 1})\end{array}$ \\
\hline $\begin{array}{l}\text { Complex procurement } \\
\text { efficiency indicators }\end{array}$ & Internal & & & $\mathrm{A}, \mathrm{B}, \mathrm{C}, \mathrm{D}, \mathrm{E}$ \\
\cline { 2 - 5 } $\begin{array}{l}\text { Comprehensive quality } \\
\text { indicators }\end{array}$ & External & & $\mathrm{A}, \mathrm{B}, \mathrm{D}$ & $\mathrm{C}, \mathrm{E}$ \\
\cline { 2 - 5 } & Internal & $\mathrm{A}, \mathrm{C}$ & $\mathrm{B}, \mathrm{E}$ & $\mathrm{D}$ \\
\hline
\end{tabular}


As a result of evaluating the effectiveness of procurement of "TODEP" there were revealed following weaknesses in the procurement in the internal environment of such branches as Tyumen RRCD, Yalutorovsk RRCD: repeated duplication of requests for material resources coming from different parts of the branches, low data rate applications to the head office, the lack of adequate quality control of material resources and compliance with delivery deadlines, etc.

\section{Conclusions}

The proposed procedure for evaluating the effectiveness of procurement management system consists of four groups of indicators that will allow an assessment of the effectiveness of the planning, organization and control of procurement, as well as identify existing weak points in the procurement process. Carrying out of estimation is possible by comparing the dynamics of the results (compared with the previous periods), or by using as a benchmark the best parameters of similar entities of the industry.

In order to confirm the applied nature of the author's recommendations there was assessed procurement activity evaluation of road-building organization and on its basis there was formed the development path of procurement activity, supported by logistics and management tools. Map of evaluation the procurement effectiveness is proposed to be used as a tool for monitoring of procurement activity in the dynamics. Formed and tested procedure for assessing the procurement efficiency in the organization of "TODEP" confirmed its effectiveness in the substantiation of procurement development directions, taking into account the influence of factors of internal and external environment.

In general, the study results broaden and deepen the submission of procurement and open up prospects for the further development of procurement analysis and evaluation methods that improve the efficiency of production and economic activities of organizations.

\section{References}

1. A.G. Butrin, Yu.G. Amerhanova, Integratedlogistics, 4, 20 (2009)

2. V.P. Fedko, V.A. Bondarenko, Commerciallogistics, 304 (2006)

3. V.V. Scherbakov, Logistics and Supply Chain Management, 582 (2015)

4. A.A. Kanke, I.P. Koshevaya, Logistics bases, 576 (2013)

5. Yu.G. Lebedev, Logistics harmonized supply chain, 448 (2005)

6. A.P. Tyapukhin, Design of distribution systems based on logistics, 240 (2007)

7. L.B. Mirotin, A.K. Pokrovsky, Fundamentals of Logistics, 192 (2013)

8. M. Linders, F. Johnson, A. Flynn, H. Fearon, Procurement and Supply Management, 752 (2014)

9. D. Bauersoks, D. Kloss,Logistika: integrated supply chain,640(2010)

10. Yu.A. Borodina, O.M. Syardova. Thestrategyofsustainabledevelop18, 56 (2013)

11. A.V. Sysolyatin, Electronic scientific journal13, 1-7(2015)

12. V.S. Lukinskiy, V.V. Lukinskiy, N.G. Pletnev, Logistics and SCM, 360 (2016)

13. V.I. Sergeev, Corporate Logistics, 976 (2008)

14. V.I. Sergeev, I.P. Elyaschevich. SupplyLogistics, 398 (2016)

15. A.Kopytova, Procedia Engineering165, 1132 (2016)

16. M.N. Grigoryev, V.V.Tkach, S.A. Uvarov,Commerciallogistics, 490 (2016) 
17. A.Yu. Minnullina,Economics and Entrepreneurship5-2, 734(2014)

18. A.V. Kemenov,Logistics building complex,320 (2012) 